This article has been published in a revised form in the International Journal of Discrimination and the Law [https://journals.sagepub.com/home/jdi]. This version is free to view and download for private research and study only. Not for re-distribution or re-use. (C) Alysia Blackham.

\title{
Does removing default retirement ages benefit individuals? A comparative empirical case study of the university sector
}

\begin{abstract}
Alysia Blackham
In 2011, the UK government abolished the national default retirement age. While this could support extended working lives and promote individual choice, it could also be a neoliberal 'ploy' to individualise the risks of old age. The question, then, is what impact does the removal of mandatory retirement have in practice: does it help to promote individual choice and autonomy? Or does it simply lead to work intensification and the individualisation of the risks of demographic change? Or both, perhaps simultaneously?
\end{abstract}

Drawing on original qualitative and quantitative empirical data from UK and USA universities, this article considers the impact of removing mandatory retirement ages on individual workers in higher education. It argues that legal reform may have promoted or encouraged work intensification in universities, including through an increased focus and use of performance management. Thus, in practice, the consequences of removing retirement ages for individuals are mixed.

Keywords: age discrimination, retirement age, universities, work, intensification, performance management, United Kingdom 


\section{1) Introduction}

Abolishing the national default retirement age ('DRA') in 2011 has transformed UK workplace relations. Rather than relying on fixed retirement ages, employers must now generally manage and negotiate retirement on a case-by-case basis. While employers may adopt an EmployerJustified Retirement Age ('EJRA') there remains significant uncertainty regarding when a retirement age will be 'justified'. As a result, perhaps, many employers chose to remove fixed retirement ages, rather than risk a legal challenge (DWF, 2012).

Removing mandatory retirement ages could be seen as promoting extended working lives, enhancing individual choice around when to retire, and supporting the sustainability of pension systems (Beck and Williams, 2015: 268; Manfredi and Vickers, 2013a: 255). Conversely, it could be seen as a contrived policy device to further individualise the risks of ageing and old age, justifying further increases to state pension ages and advancing a neoliberal agenda to wind back the welfare state (Macnicol, 2015; Manfredi and Vickers, 2013a: 259-262). The removal of mandatory retirement may therefore not be in individuals' interests, particularly if it leads to work intensification, a renewed focus on performance management, and lesser tolerance of reduced productivity in old age (Beck and Williams, 2015). The question, then, is what is the impact of removing mandatory retirement ages? Does it help to promote individual choice and autonomy? Or does it simply lead to work intensification and the individualisation of the risks of demographic change? Or both, perhaps simultaneously?

Universities offer a valuable context for examining how changes to retirement ages are impacting upon individuals and organisations. Universities have traditionally relied on retirement ages as a workforce management tool (Manfredi and Vickers, 2009: 364, cf 2013b: 293). Many academics find their work rewarding and wish to continue in their post into older 
age (see, for example, Rosenman and McDonald, 1995: 63). In a survey of academic staff at 12 UK higher education institutions, 29 per cent indicated that they would prefer to retire over the age of 65 and 36 per cent expected to retire after the age of 65 (Manfredi and Vickers, 2009: 357). This means that universities are particularly exposed to the removal of mandatory retirement, and the higher education sector offers a critical illustration of the possible impacts of moving to a world without retirement ages.

Previous studies have considered specific concerns related to the abolition of the DRA in universities, often drawing on comparative perspectives. For example, considering the Australian experience, I have canvassed the possible implications of removing mandatory retirement for the performance management of academic staff, the creation of opportunities for new generations of academics and the scope for workforce planning (Blackham, 2015a). However, there has been minimal discussion of how UK universities are actually responding to the abolition of mandatory retirement, and whether these concerns are eventuating in practice in the UK context (Blackham, 2019a). Further, there has been limited empirical consideration of the impact of removing retirement ages on individuals.

This article addresses this lacuna, presenting original qualitative and quantitative empirical data regarding how UK universities are responding to the abolition of mandatory retirement, and the potential impacts of removing retirement ages on individuals. After commencing with brief discussion of the law relating to retirement ages in the UK (Part 2), I consider the ways in which removing retirement ages might assist or hinder individuals at work (Part 3). In Part 4, focusing on the issues of performance management and work intensification, I evaluate the extent to which these concerns are eventuating in practice, drawing on a quantitative survey of all UK universities and Oxford and Cambridge colleges, and organisational case studies of 
seven UK universities. These empirical findings from the UK are compared with comparative case studies of six US universities. Higher education institutions in the US have been operating without fixed retirement ages since 1994, meaning they have had a much longer period in which to adapt to the removal of mandatory retirement. While there are clear differences between the legal framework and higher education in the UK and US - particularly relating to the tenure system, funding of higher education, institutional wealth and health insurance - the US experience may offer insights into the sort of equilibrium UK universities might achieve with an ageing workforce post-DRA, offering additional and complementary insights to existing research on Australian universities (Blackham, 2015a, 2016a).

\section{2) The law relating to retirement ages in the UK}

Statutory protection of retirement ages in the UK was retained even with the introduction of age discrimination legislation: an exception for dismissal on the basis of retirement was included in the Employment Equality (Age) Regulations 2006 reg 30 for workers at or over the age of 65 , creating a national DRA. Employers were also able to retain a lower retirement age if it could be objectively justified. The Employment Equality (Repeal of Retirement Age Provisions) Regulations 2011 abolished the DRA and removed retirement as a fair reason for dismissal in the Employment Rights Act 1996. However, employers may still adopt an EJRA so long as it can be objectively justified as a proportionate means of achieving a legitimate aim (Manfredi and Vickers, 2013b: 299-308).

It is still difficult to predict when an EJRA will be legally 'justified'. While it should be fairly straightforward to identify legitimate aims to support a retirement age, with the UK Supreme Court endorsing those relating to both intergenerational fairness (Dewhurst, 2013) and dignity (Blackham, 2019b), ${ }^{\mathrm{i}}$ it will be harder to prove that a particular retirement age adopted is 
proportionate. Perhaps as a consequence of this legal uncertainty, employers generally appear unwilling to adopt an EJRA; early surveys of employers put the percentage adopting an EJRA as anywhere between 2.9 per cent (Eversheds, 2013:2) and 19 per cent of respondents (Thomas et al., 2013: 9). Thus, mandatory retirement is now the exception, rather than the norm, in the UK.

\section{3) The impacts of removing mandatory retirement ages}

Removing mandatory retirement was originally aimed at promoting extended working lives, enhancing individual choice around when to retire, and supporting the sustainability of pension systems, the economy and the labour market (Beck and Williams, 2015: 268; Manfredi and Vickers, 2013a: 255). Providing older workers with stronger legal protection at the end of working life could also help to reduce precarious work among older age groups, though the empirical results of these changes are mixed (Blackham, 2016b).

That said, the consequences of removing mandatory retirement are unlikely to be all positive. There is a general consensus among employers and governments that changes to retirement ages will lead to an increase in the use of, and dismissals based on, capability and performance measures (BIS, 2011: 3, 6). This was also thought to be the case in the university sector (Manfredi and Vickers, 2013b: 295), despite universities traditionally having had weak (or non-existent) procedures for performance management, particularly for academic staff (Guest and Clinton, 2007: 6). Beck and Williams (2015) have argued that a renewed focus on performance management with the removal of retirement ages has increased employer discretion about who remains in employment (and for how long); individual choice is significantly constrained by employer processes. Only those in the higher segments of the labour market - with high levels of human capital, and a pension - are therefore likely to have 
genuine choice about when they retire (Manfredi and Vickers, 2013a: 256). In essence, then, formal equality on the basis of age has been achieved at the expense of fairness at work (Beck and Williams, 2015).

A renewed focus on performance could also drive work intensification for workers of all ages. As Taylor (2013: 33) synthesizes, work intensification relates to the 'amount of work/effort required of, and performed by, workers in each unit of time (intensity) and an increase in the amount of work/effort between comparable units of time over time (intensification).' Intensification can be attributed to both job insecurity (that is, market control) and internal systems of control within the organisation (Green, 2001, 2004; McGovern et al., 2007: 129130; Taylor, 2013: 34-35). This implies, then, that job intensification in higher education can be at least partly connected to growing precarity in the academic job market, shifts in higher education funding, and the increasingly competitive global market for higher education (Ogbonna and Harris, 2004: 1186-1188). However, it is also related to the 'growth of systematic [human resource management] practices that are geared to high commitment or high performance' (McGovern et al., 2007: 129) put in place to monitor, assess and incentivise workers, including through systems of performance management. While performance management does not necessarily need to drive work intensification, that can be the result of the way it is currently deployed by many organisations. Higher work intensity is associated with fatigue, stress, and lower work-life balance (Boxall and Macky, 2014: 971), and declining morale and job satisfaction in higher education (Bryson, 2004). It is therefore a concern for individuals, institutions and the academic enterprise as a whole (Hartman and Darab, 2012).

While removing retirement ages may prompt employers to focus more on performance management, this does not mean that older age actually causes declining capacity (Bytheway, 
2005: 339; Duncan, 2008: 1143). The assumed link between age and capacity is typically driven by ageist beliefs about the ageing process (Bytheway, 2005: 339), falsely using age as a proxy for capability (Fredman, 2003: 40) and adopting a 'decline' theory of ageing which ignores the potential benefits of ageing (Moughton and Manfredi, 2011: 25) and the social construction of age (Schaie, 2001: 320). Age is a weak indicator of capacity for productive work (Bass and Caro, 2001: 40), especially given heterogeneity in the ageing process (Evans, 2003: 16). Ageist attitudes and work cultures have a far more direct impact on older workers' performance than chronological ageing (Koopman-Boyden and Macdonald, 2003: 34). Despite this, employers may still assume that 'older workers [will] decline in competence and capability as they [age]' (Sargeant, 2010: 250). This implies, then, that the removal of mandatory retirement may drive a renewed focus on performance management and work intensification, even if age is not a driver of underperformance.

Overall, then, it is still unclear how the removal of mandatory retirement will play out in UK organisations, and in universities in particular: will it help or hinder individual workers? Will it just lead to stronger managerial control of academic work, and work intensification? The sections that follow consider these questions, using empirical data from UK and US universities.

\section{4) Does the removal of retirement ages help or hurt individuals? Evidence from UK and US universities}

To evaluate the potential impact of removing retirement ages on individuals, and assess whether these concerns are eventuating in practice, this study draws on quantitative and 
qualitative evidence from UK and US universities. Mixing qualitative and quantitative data in this way helps to overcome the limitations of any one research method (Hesse-Biber, 2010).

The data collected as part of this study canvassed a range of areas, with the aim of considering the issues (if any) arising in UK universities following the abolition of the DRA. In this article, I focus on the implications of removing mandatory retirement for performance management and work intensification, reflecting concerns that the three are likely to be linked (Manfredi and Vickers, 2013b: 296-7; Blackham, 2015a: 510, 524, 2019b: 408-10). That said, in Australia, I found that the removal of mandatory retirement did not lead to more rigorous performance management in universities, perhaps due to their limited capacity and inclination to use performance processes in this way (Blackham, 2015a: 523-4, 2016a: 154-5); similar reluctance may emerge in UK universities (Blackham, 2015a: 508-9).

To assess these questions, quantitative data was obtained from a survey sent to all UK universities and all Oxford and Cambridge colleges (220 institutions in total) via Freedom of Information (FOI) requests. After multiple follow-ups, responses were ultimately received from 169 institutions over the course of 2015 (a response rate of 76 per cent). Quantitative institutional data is unlikely to capture the full range of performance processes that are occurring in practice; in many cases, performance is likely to be dealt with informally, and processes not recorded centrally. The statistics from the survey were therefore triangulated and corroborated with organisational case studies of seven UK universities, including three universities that adopted an EJRA, and four that are operating without a retirement age (each identified with a $U$ and a number, and each interviewee identified with a letter). ${ }^{\text {ii }}$ A case study methodology was selected for this research as it enabled the complexity of the employment of older university workers to be studied in depth and interpreted in the organisational context 
(Feagin et al., 1991: 7-13; Simons, 2009: 23). Cases were sampled purposively to reflect different organisational and university structures that were predicted to influence their exposure and response to an ageing academic workforce: both established, research-intensive universities and newer, more teaching-focused universities were selected for study. A final determination and selection of cases was made based on practical considerations, including whether the university was physically accessible to the researcher (Patton, 1990: 181).

The case studies included semi-structured interviews with Directors or senior members of the universities' Human Resource, Legal Services and/or Equality Units, and a documentary review of university policies and other documents. Interviews were also conducted with institutional representatives of the University and College Union where possible. Nine interviews were conducted in total across the UK, considering how an ageing workforce was affecting the university, measures taken to support older academics, and their practical success. Each interview took around an hour; each was digitally recorded, transcribed and analysed using NVivo software. Interviews were analysed using content analysis to identify, code and categorise key patterns in the data (Patton, 1990: 381) with reference to the questions respondents were asked and themes derived from the literature.

\section{a) Avoiding performance management as a justification for adopting an EJRA}

The UK courts have recognised that the removal of retirement ages might result in an increase in performance management; avoiding performance management at the end of work careers or maintaining older workers' 'dignity' - might therefore be a legitimate aim supporting a retirement age ${ }^{\text {iii }}$ Most UK universities have chosen not to adopt an EJRA, with the exception of Oxford (and some of its colleges), Cambridge (and some of its colleges), St Andrews, and Westminster. In these 'EJRA institutions', the need to avoid performance management was a 
recurring - though not the dominant - justification for adopting a retirement age. The potential complexities of adopting an EJRA on this basis are well illustrated by the case of the University of Oxford.

According to the University of Oxford, their EJRA was originally supported by seven legitimate aims, one of which was 'avoiding invidious performance management and redundancy procedures' when terminating staff 'at the end of a long career' (Personnel Services, University of Oxford, 2015). This EJRA justification was cast into doubt by an internal appeal to the University's Appeal Court in September 2014 (Galligan, 2015). The Appeal Court decided that the Oxford EJRA was not objectively justified, and that the removal of a staff member following a failed application to continue in employment was an unfair reason for dismissal. In its decision, the Appeal Court doubted whether avoiding performance management was a legitimate aim (Galligan, 2015). The Appeal Court's decision was only binding in relation to the situation of that particular staff member, and did not create any binding precedent for the university generally (Goss, 2015: 6). However, the Oxford EJRA was ultimately amended, including to remove avoiding performance management as a justification (University of Oxford, 2017). A challenge to the Oxford EJRA in the Employment Tribunal in 2019 was unsuccessful, ${ }^{\text {iv }}$ and the EJRA was held to be a proportionate means of achieving a legitimate aim. The University did not rely on avoiding performance management as an aim in support of the EJRA. ${ }^{v}$ However, the Tribunal decision noted that the University had considered other options, including performance management, as an alternative to the EJRA, but that 'The University's academics ... turned their backs against the introduction of performance management as the consensus was that it would be demeaning to those who are at the end of their academic careers. ${ }^{\text {vi }}$ Thus, avoiding performance management may help to justify an EJRA, if only obliquely. 
Similarly, in the organisational case studies, performance management was not a frequent concern in the EJRA institutions: one university, for example, noted that concerns about intergenerational fairness were far more important than performance concerns. That said, one university noted that it had experienced significant difficulties when attempting previously to introduce performance management for academic staff: 'there is a real issue here with any mention of performance management'. Without performance management, an EJRA effectively became the university's 'only option'. Another university respondent felt that performance management was difficult to reconcile with academic freedom. An EJRA was therefore seen to 'complement' an institution with no performance management, though the respondent noted that there was no good evidence that performance deteriorates with age.

Thus, avoiding performance management was seen as only one possible rationale for retaining a retirement age, though this was not uniformly accepted and was not seen as a priority in all institutions. It is therefore revealing to consider how performance management is operating in universities that removed their retirement age in 2011.

\section{b) Performance management in non-EJRA institutions}

In the FOI survey, institutions without an EJRA were asked: 'Has the university/college experienced any problems operating without a retirement age?' Non-EJRA universities did not identify any relevant problems, though some noted that they did not hold any documentation on this point. ${ }^{\text {vii }}$

Non-EJRA institutions were also asked how unsatisfactory performance was dealt with for staff at their institution, and to provide a copy of any documents explaining how the process worked (such as guidelines or policies). The vast majority of responding non-EJRA institutions 
(137 respondents $)^{\text {viii }}$ had performance management processes in place and could provide a copy of their policy or procedure. There were only three exceptions: the London School of Economics noted that it had no actual performance procedure for academic staff, though one had been proposed, and performance issues could be covered by the existing disciplinary procedure; the University of London, which had no formal performance or capability policy or procedure; and Arts University College Bournemouth, which reported having no capability process in place.

While having performance processes was the norm, it appeared that few institutions were formally making use of these policies in practice. Respondents with a process for managing unsatisfactory performance by staff were asked: 'How many staff aged 50 or above were subject to this process in the a) 2013 and b) 2014 calendar years?'. The results for these questions are included as Table 1. A substantial number of institutions reported holding no central data on performance management, or reported not breaking that data down by age. Of those who kept central data, the majority reported fewer than five individuals aged 50 and above being subject to a performance process each year, though the number of performance processes increased from 2013 to 2014. Thus, while most institutions have performance policies in place, these are not being formally utilised in practice, at least for those aged 50 and above.

$<$ Insert Table 1 about here $>$

Institutions were also asked to break down these figures for academic and support staff, to determine whether particular groups were more likely to be subject to formal performance processes, as depicted in Table 2. Support staff aged 50 and above appear slightly more likely 
to be subject to performance processes than academic staff of the same age, though this may reflect higher numbers of support staff overall.

$<$ Insert Table 2 about here $>$

Of course, these institutional figures do not capture informal performance processes, or management discussions that might not be centrally reported. Indeed, some institutions noted that they specifically tried to promote informal processes for managing performance issues. Thus, these figures are unlikely to capture the full extent to which performance discussions are actually occurring in practice.

Given the small numbers involved, it is also difficult to tell whether the use of performance processes for those over the age of 50 is disproportionately high, at least when compared to the general staff population. Table 3 offers a comparison between performance processes used for staff aged 50 and over and the general university population (all ages), broken down by academic and support staff.

$<$ Insert Table 3 about here $>$

The organisational case studies demonstrate that the removal of the DRA has forced some universities to consider issues of performance management afresh, even if age is not necessarily linked with declining performance (U3). One institution was developing a new performance and development framework that explicitly required staff of all ages to consider their career plans and aspirations (U3). Thus, the removal of the DRA had meant that 'we do have to start addressing performance management more seriously' (U3). At the same time, the university's 
performance processes were limited by its statutes, which made it a 'longwinded, very difficult process to move through to actually dismissal' (U3). It is perhaps unsurprising, then, that very small numbers of staff were put through this process.

Another institution noted that it had 'no significant tradition' of performance management, which often meant that underperformance went unaddressed (U4). Thus, with the removal of the DRA there were 'serious moves' to look at the whole issue of performance management (U4), and to address performance issues when they emerged (U4). This was giving strong impetus to the human resources agenda, which had been noting the need for performance management for years (U4). The removal of the DRA had therefore become a lever for introducing proper performance processes and systems, though the institution had 'a long way to go' on this issue (U4). Managers were still reluctant to have difficult conversations with their employees, including about their future employment intentions (U4), and the culture remained one of tentativeness and reluctance to address performance issues (U4).

While one university had a stronger culture of performance management, and was increasingly moving away from the 'collegiate romance' (U5a, also U5b), there were still pockets where performance and development reviews were not being conducted, and with 'hazy' line management (U5a). There had been a push to introduce permanent academic heads of department, to ensure that someone was willing to tackle difficult management issues (U5b). However, there was still anecdotal evidence that, even without a retirement age, managers were not addressing declining performance, and instead were 'waiting it out' until individuals voluntarily retired (U5b). As much as age was not necessarily associated with declining performance, there was possibly a perception of older professors 'coasting on past achievements', which was not always warranted (though it might be true in some cases) (U5a, 
also U5b). While performance management was hard (U5a, U5b), it was not only being pushed as a result of the removal of the DRA. Indeed, higher student expectations, the need to be more competitive for grant funding, a more competitive international student market (U5a) and pressure from the Research Excellence Framework (U5b) were all encouraging a stronger focus on performance issues.

This may also reflect a more general shift in how academic work is perceived, and the place of performance management in academic institutions. One respondent questioned some interpretations of 'academic freedom' (that is, as prohibiting performance management), noting that it was possible to have academic freedom and still be subject to steering from the university (U3). Another interviewee argued that the idea that performance management was antiacademia was a 'huge conspiracy', and that academic work was not as special as many argue (U4). Indeed, it is arguably relatively easy to measure academic success (e.g. via quantitative measures such as teaching scores and research outputs) (U4). Given the comparatively generous level of academic salaries, it was seen to be right to require that academics actively engage with their job (U4). Thus, some non-EJRA institutions arguably viewed academic work in a fundamentally different way to EJRA institutions; indeed, one non-EJRA university respondent explicitly rejected as normatively undesirable the use of an EJRA to address declining academic performance (U1b).

\section{c) Work intensification, working time and retirement}

In my previous work, I argue that a renewed focus on performance management in Australia following the removal of mandatory retirement has led to work intensification in academia (2015a: 510, 524). Work intensification and workload are recurring issues in academia; this has been the case even prior to the removal of mandatory retirement ages. In the UK, institutions have seen growing referrals to counselling and occupational health services 
(Morrish, 2019), increasing stress and declining wellbeing among staff (Deacon, 2018; Kinman and Wray, 2013; Tytherleigh et al., 2005). The intensification of academic work, like a stronger focus on performance issues, is due to a number of overlapping factors, being both internally and externally driven. What is clear, however, is that academics are being expected to do more, to appease a wider range of stakeholders, and to be high achieving across a broad portfolio of skills and expectations. This has undeniably led to work intensification in the sector and the growth of a long hours culture (Sang et al., 2015), and may be further exacerbated by a renewed focus on performance management.

However, work intensification affects people differently. It is unclear, for example, whether older workers are particularly vulnerable to the effects of work intensification (Mauno et al., 2019); more likely, the heterogeneity of the 'older worker' cohort means that the effects of work intensification will vary markedly across the workforce.

That said, older academics (and, in particular, those with decent pensions) may have more choice than younger workers in how they manage work intensity. Work intensification may therefore have implications for intergenerational fairness in academia, in addition to the more general concerns about the intergenerational fairness of removing retirement ages (Blackham, 2015a: 510-12, 526-8). For example, older academics appear to be making extensive use of part-time work arrangements, perhaps in part to manage the growing demands of their role and to reduce the physical and mental impacts of work intensification. This is demonstrated by Table 4, which shows the substantial growth in part-time academic staff among those over the age of 61. Part-time working has become the preferred option for older academics in the UK.

$<$ Insert Table 4 about here $>$ 
Flexible working is generally regarded as a key tool for extending working lives, and can be the preferred form of work for some older workers (Blackham, 2015b). Part-time work may become a form of phased retirement, as people scale down their work responsibilities prior to fully retiring. While part-time work may also help older academics manage the demands of work intensification, the luxury of part-time working (and associated pay cut) is an option only available to the most financially successful academics, or those who can take a part pension; flexible work is 'limited to those with more advantaged work histories and life circumstances' (Loretto and Vickerstaff, 2015: 244). It is unlikely to help younger or less well-off academics manage the increasing demands of their jobs. Thus, work intensification is a particular challenge for those who are more junior or receiving lower pay.

At the same time, those who remain in academic employment into older age tend to be men on higher salaries. In 2015-16, of full-time academic staff aged 66 and over in the UK, 59\% were on a contract salary exceeding $£ 58,754$ (the top rate surveyed), compared with $20 \%$ of fulltime academic staff across all age groups (see Table 5). As a percentage of those in academic appointments, women declined from $24.9 \%$ of professors aged $56-60$, to only $13.9 \%$ of professors aged 66 and over (see Table 6). This implies that women are more likely to retire than their male counterparts after the age of 60 .

\footnotetext{
$<$ Insert Table 5 about here $>$

$<$ Insert Table 6 about here $>$
} 
Thus, the individuals who are benefitting from the removal of mandatory retirement ages appear to be well paid men, who are able to move to a part-time working arrangement. This is unlikely to be the group who need the financial benefit of longer working lives. The idea of 'extending working lives' may therefore serve to 'intensify cultural and structural discrimination' facing women in the workforce (Loretto and Vickerstaff, 2015: 245). The interaction of legal change and organisational practice in universities has arguably led to unintended consequences which are detrimental to workforce diversity.

It is in relation to these unintended consequences of legal change and work intensification that the findings from US university case studies are particularly pertinent. Six US case study organisations were sampled purposively from research-intensive universities (each identified with an $\mathrm{A}$ and a number). Case studies included semi-structured interviews with human resources directors, university management, unions, members of equity committees and staff (particularly older academics and early career academics). A documentary review was also undertaken of university policies. In total, 10 interviews were conducted in the US across three states. Interview data was analysed in the same way as the UK interview data.

The US experience may offer insights into the sort of equilibrium UK universities might achieve with an ageing workforce post-DRA. The tenure system at some US universities limits the ability to remove academic staff for underperformance (A5a), including into older age. Thus, as in the UK, performance management can be difficult in the US university context. However, one US university reported adopting a system of post-tenure review, where individuals have their performance assessed every five years, even after achieving tenure, though these processes have different levels of 'teeth' and impact in different parts of the university (A1a). The post-tenure review system was seen as being 'very helpful', including in 
keeping people on track with their research and career and in promoting a high productivity culture (A1c). For those without a system of post-tenure review (A3a, A4, A5a), some reported that a high-performance culture compels performance (A5a, A5b); others employed many staff on fixed-term contracts, allowing discussions of performance at the end of each fixed-term period (A4); or made pay increases for tenured staff conditional on performance reviews (A4, A1a). Even where institutions had performance policies (A1a), these were rarely invoked in practice (A1c): that said, just the threat of the policy could be sufficient to boost performance (A1a).

US universities do not typically facilitate part-time work arrangements for staff: part-time work is either not available or severely restricted (A5b, A2). This contrasts with the UK, where all staff have a statutory right to request flexible working (including in the form of part-time work). ${ }^{\text {ix }}$ In a performance-focused culture, with ongoing review and assessment, and no or very restricted provision of part-time work, universities reported using part-time work as leverage (A4) to encourage staff to enter into a retirement agreement (A4, A5a, A5b, A3, cf A2). Staff became weary of undertaking a full academic load, which was often more than 40 hours per week (A1a). In one institution, it was feared that no one would ever retire without the prospect and incentive of part-time work, particularly given staff often lost their medical insurance upon retirement (A4). That same institution had created a part-time route to retirement in institutional policies, formalising the informal practices that had been occurring in certain departments (A4). That said, using part-time work as a retirement incentive did not work at one institution, which had a final salary defined benefit pension system (A1c). In this pension context, the financial penalty of part-time work likely exceeded its perceived benefits. 
Restricting part-time work to those who are retiring has gendered implications: workload (and excessive workload) and gender equity are closely related (A1b). Being a member of Faculty is 'very demanding'; especially with a family, there is not time to do all the things required of an academic staff member (A1b). Thus, work intensification is a particular problem for those who are early in their career, or who are caring for young families, who can be seen as "not working hard enough' (A1b). Being a family-friendly employer requires institutions to actually improve the work situation, rather than just requiring people to 'work and work and work and work' (A1b).

\section{5) Discussion and conclusions}

Returning to our original question - what is the impact of removing mandatory retirement ages?

- it is clear that empirical evidence is still mixed. Early qualitative and quantitative data from the UK university sector provides some evidence that universities are renewing their focus on performance management with the removal of the DRA. However, formal performance processes are still rarely used for staff at universities, regardless of their age or job role. That does not mean that performance processes are not having an impact on work culture and expectations; the informal impact of performance processes may be more significant than these statistics imply. While performance management is part and parcel of the 'neoliberal university' (Lorenz, 2012) its significance and importance appears to have been further reinforced by the removal of mandatory retirement.

More generally, though, these findings raise doubt that the removal of mandatory retirement will actually increase individual choice about when to retire. Managerial prerogative is reinforced through performance processes that determine which staff can remain at work into older age (Beck and Williams, 2015). Indeed, as the US case studies illustrate, growing work 
intensification can drive people towards retirement; the lure of part-time working then becomes an effective incentive to relinquish tenure. The US case studies therefore illustrate the potential use of work intensification and inflexibility as an alternative to fixed retirement ages.

In the UK, of course, part-time working is more freely available and (comparatively) normalised. It appears that many older academics are using part-time work to negotiate complex work demands: in 2012-13, for example, academics aged 61 and over were more likely to be working part-time than full-time. This has three implications: first, it means that UK universities lack a key tool or carrot to encourage academics to retire. This may mean that removing mandatory retirement ages in the UK has a greater impact than in the US. The results in this article capture the early days of UK universities operating without mandatory retirement. Future years are likely to see increased pressure on performance management in universities, potentially driving work intensification. Thus, these findings foreshadow possible developments in years to come.

Second, then, these findings mean that more attention must be paid to who is able to utilise part-time or flexible working, particularly on the basis of gender and caring responsibilities. There is a need to examine the way 'gender roles are maintained, intensified or even challenged over the course of the working life', particularly in the lead up to retirement (Loretto and Vickerstaff, 2015: 246).

Third, and relatedly, we must be attuned to the risk of work intensification, and its implications for workers of all ages, particularly those with caring responsibilities. If UK universities are to monitor and assess these risks, they must adopt better data management processes. The responses to the FOI requests present a worrying lack of information in this area; many 
universities did not centrally collect or monitor data on performance management. Better gathering and analysis of workforce data is key.

It is not assured that universities will experience negative consequences as a result of the removal of the DRA. Indeed, universities may experience improved staff retention, increased workforce morale and retention of vital skills and experience. Individuals may benefit from greater choice around how they structure their work careers. The risk, though, is that a fear of an ageing workforce drives a growth in performance management and work intensification; this is likely to negatively affect all workers in the higher education sector. While the removal of retirement ages could be a positive development for employers and employees, it is largely in employers' hands to determine how this plays out in the future. There is a need for better work conditions for all workers, regardless of age, and a renewed focus on how to reduce or ameliorate work intensity.

\section{6) Statement of ethical approval}

This study had ethical approval from the University of Cambridge and the University of Melbourne (ethics ID 1646903).

\section{7) Statement of funding}

The author disclosed receipt of the following financial support for the research, authorship, and/or publication of this article: This work was supported by a Research Activities Fund Grant from the Society of Legal Scholars, and a Research Grant from the Socio-Legal Studies Association Grants Scheme. These funders played no role in the design, execution, analysis and interpretation of data, or writing of the study. 


\section{8) Statement of conflict of interest}

The author declares no conflict of interest.

\section{9) Notes}

\footnotetext{
i Seldon v Clarkson Wright \& Jakes (A partnership) [2012] 2 CMLR 50, [56]-[57] ('Seldon').

ii Where identifying the university would jeopardise source anonymity (eg for universities with an EJRA, which are few in number and publicly known), no source has been cited.

iii Seldon [56]-[57].

iv Pitcher v University of Oxford [2019] UKET 3323858/2016.

${ }^{v}$ Ibid [396].

vi Ibid [109], [404].

vii Technically this question was beyond the scope of what could be asked in a FOI request. The author is grateful to the institutions that answered the question regardless.

viii Many institutions provided incomplete responses to the survey questions, meaning total figures are variable for each question.

ix Employment Rights Act 1996 (UK) s 80F.
}

\section{0) References}

Bass SA and Caro FG (2001) Productive aging: a conceptual framework. In: Morrow-Howell N, Hinterlong J, and Sherraden MW (eds) Productive Aging: Concepts and Challenges. Baltimore: John Hopkins Press, pp. 37-80.

Beck V and Williams G (2015) The (Performance) management of retirement and the limits of individual choice. Work, Employment \& Society 29(2): 267-277. DOI: $10.1177 / 0950017014559963$.

BIS (2011) Phasing out the default retirement age: government response to consultation. URN 11/536, 13 January. London.

Blackham A (2015a) Managing without default retirement in universities: a comparative picture from Australia. Legal Studies 35(3): 502-31. DOI: 10.1111/lest.12079.

Blackham A (2015b) Rethinking Working Time to Support Older Workers. International Journal of Comparative Labour Law and Industrial Relations 31(2): 119-140.

Blackham A (2016a) Organisational Responses to the Abolition of Mandatory Retirement: Case Studies of Australian University Practice. Industrial Law Journal 45(2): 144-175.

Blackham A (2016b) Reforming Default Retirement Ages: Regulating Out Precariousness for Older Workers? European Labour Law Journal 7(1): 4-30. DOI: $10.1177 / 201395251600700102$. 
Blackham A (2019a) An experimentalist approach to equality: a case study of retirement in the UK university sector. Legal Studies 39(4): 598-617. DOI: 10.1017/1st.2018.53.

Blackham A (2019b) Interrogating the 'Dignity' Argument for Mandatory Retirement: An Undignified Development? Industrial Law Journal 48(3): 377-415. DOI: 10.1093/indlaw/dwy013.

Boxall P and Macky K (2014) High-involvement work processes, work intensification and employee well-being. Work, Employment and Society 28(6): 963-984. DOI: $10.1177 / 0950017013512714$.

Bryson C (2004) What about the workers? The expansion of higher education and the transformation of academic work. Industrial Relations Journal 35(1): 38-57. DOI: 10.1111/j.1468-2338.2004.00299.x.

Bytheway B (2005) Ageism. In: Johnson ML, Bengtson VL, Coleman PG, et al. (eds) The Cambridge Handbook of Age and Ageing. Cambridge: Cambridge University Press, pp. $338-45$.

Deacon T (2018) The crippling stress university lecturers face. Available at: https://www.walesonline.co.uk/news/wales-news/overworked-undervalued-cripplingstress-university-15422303 (accessed 1 August 2019).

Dewhurst E (2013) Intergenerational balance, mandatory retirement and age discrimination in Europe: how can the ECJ better support national courts in finding a balance between the generations? Common Market Law Review 50(5): 1333-62.

Duncan C (2008) The dangers and limitations of equality agendas as means for tackling oldage prejudice. Ageing \& Society 28(8): 1133-58. DOI: 10.1017/S0144686X08007496.

DWF (2012) De-regulation of retirement —one year on. Available at: http://web-archiveuk.com/uk/d/dwf.co.uk/2012-07-

19_157064_88/DWF_gt_De_regulation_of_Retirement_One_Year_On/ (accessed 15 May 2012).

Evans JG (2003) Age discrimination: implications of the ageing process. In: Fredman S and Spencer S (eds) Age as an Equality Issue: Legal and Policy Perspectives. Oxford: Hart, pp. 11-20.

Eversheds (2013) Eversheds UK HR e-briefing: how are employers managing without the default retirement age? April. London.

Feagin J, Orum A and Sjoberg G (1991) Introduction: the nature of the case study. In: Feagin J, Orum A, and Sjoberg G (eds) A Case for the Case Study. Chapel Hill: University of North Carolina Press, pp. 1-26.

Fredman S (2003) The age of equality. In: Fredman S and Spencer S (eds) Age as an Equality Issue: Legal and Policy Perspectives. Oxford: Hart, pp. 21-69.

Galligan DJ (2015) Goodbye to the EJRA. Oxford Magazine (Noughth Week, Hilary Term): 4-6. 
Goss S (2015) Consideration of comments on the EJRA made by the University's Appeal Court. Oxford Magazine (Noughth Week, Hilary Term): 6.

Green F (2001) It's Been A Hard Day's Night: The Concentration and Intensification of Work in Late Twentieth-Century Britain. British Journal of Industrial Relations 39(1): 5380. DOI: $10.1111 / 1467-8543.00189$.

Green F (2004) Why Has Work Effort Become More Intense? Industrial Relations: A Journal of Economy and Society 43(4): 709-741. DOI: 10.1111/j.0019-8676.2004.00359.x.

Guest DE and Clinton M (2007) Human resource management and university performance: final report. November. London.

Hartman Y and Darab S (2012) A Call for Slow Scholarship: A Case Study on the Intensification of Academic Life and Its Implications for Pedagogy. Review of Education, Pedagogy, and Cultural Studies 34(1-2): 49-60. DOI: 10.1080/10714413.2012.643740.

Hesse-Biber SN (2010) Mixed Methods Research: Merging Theory with Practice. New York: Guilford Press.

Kinman G and Wray S (2013) Higher Stress: A Survey of Stress and Well-Being Among Staff in Higher Education. July.

Koopman-Boyden PG and Macdonald L (2003) Ageing, work performance and managing ageing academics. Journal of Higher Education Policy and Management 25(1): 29-40. DOI: $10.1080 / 13600800305744$.

Lorenz C (2012) If You're So Smart, Why Are You under Surveillance? Universities, Neoliberalism, and New Public Management. Critical Inquiry 38(3): 599-629. DOI: $10.1086 / 664553$.

Loretto W and Vickerstaff S (2015) Gender, age and flexible working in later life. Work, Employment and Society 29(2): 233-249. DOI: 10.1177/0950017014545267.

Macnicol J (2015) Neoliberalising Old Age. Cambridge, United Kingdom: Cambridge University Press.

Manfredi S and Vickers L (2009) Retirement and age discrimination: managing retirement in higher education. Industrial Law Journal 38(4): 343-64. DOI: 10.1093/indlaw/dwp025.

Manfredi S and Vickers L (2013a) Meeting the Challenges of Active Ageing in the Workplace: Is the Abolition of Retirement the Answer? European Labour Law Journal 4(4): 251271.

Manfredi S and Vickers L (2013b) Pensioning off the mandatory retirement age: implications for the higher education sector. Legal Studies 33(2): 289-311. DOI: 10.1111/j.1748121X.2012.00247.x.

Mauno S, Minkkinen J, Tsupari H, et al. (2019) Do Older Employees Suffer More from Work Intensification and Other Intensified Job Demands? Evidence from Upper White-Collar 
Workers. Scandinavian Journal of Work and Organizational Psychology 4(1): 3. DOI: 10.16993/sjwop.60.

McGovern P, Hill S, Mills C, et al. (2007) Market, Class, and Employment. Oxford: Oxford University Press.

Morrish L (2019) Pressure Vessels: The epidemic of poor mental health among higher education staff. May. Oxford. Available at: https://www.hepi.ac.uk/wpcontent/uploads/2019/05/HEPI-Pressure-Vessels-Occasional-Paper-20.pdf.

Moughton C and Manfredi S (2011) Managing flexible retirement and extended working lives: a resource guide. Oxford.

Ogbonna E and Harris LC (2004) Work Intensification and Emotional Labour among UK University Lecturers: An Exploratory Study. Organization Studies 25(7): 1185-1203. DOI: $10.1177 / 0170840604046315$.

Patton MQ (1990) Qualitative Evaluation and Research Methods. 2nd ed. Newbury Park: Sage.

Personnel Services, University of Oxford (2015) Aim of EJRA. Available at: http://www.admin.ox.ac.uk/personnel/end/retirement/acrelretire/ejraaim/ (accessed 18 June 2015).

Rosenman L and McDonald S (1995) How should universities respond to the abolition of compulsory retirement? Australian Universities' Review 38(1): 63-6.

Sang K, Powell A, Finkel R, et al. (2015) 'Being an academic is not a 9-5 job': long working hours and the 'ideal worker' in UK academia. Labour \& Industry: a journal of the social and economic relations of work 25(3): 235-249. DOI: 10.1080/10301763.2015.1081723.

Sargeant M (2010) The default retirement age: legitimate aims and disproportionate means. Industrial Law Journal 39(3): 244-63.

Schaie KW (2001) Ageing, Theories of. International Encyclopedia of the Social and Behavioral Sciences. Elsevier Science Ltd. Available at: http://www.uwpsychiatry.org/sls/publications/Theories_aging.pdf (accessed 17 November 2011).

Simons H (2009) Case Study Research in Practice. Los Angeles: SAGE.

Taylor P (2013) Performance Management and the New Workplace Tyranny - A Report for the Scottish Trades Union Congress.

Thomas R, Bartlett E, Woollard S, et al. (2013) Recovery in sight? The state of HR. London.

Tytherleigh MY, Webb C, Cooper CL, et al. (2005) Occupational stress in UK higher education institutions: a comparative study of all staff categories. Higher Education Research \& Development 24(1): 41-61. DOI: 10.1080/0729436052000318569.

University of Oxford (2017) Aims of the Employer Justified Retirement Age (EJRA). Available 
http://www.admin.ox.ac.uk/personnel/end/retirement/acrelretire8+/erjaaims/ (accessed 15 August 2019). 


\section{1) Tables and figures}

Table 1: Number of staff aged 50 and above subject to formal performance processes, responding institutions, 2013 and 2014

\begin{tabular}{lrr} 
& $\mathbf{2 0 1 3}$ & $\mathbf{2 0 1 4}$ \\
\hline No data held & 28 & 25 \\
0 & 53 & 47 \\
$0<\mathrm{n}<5$ & 23 & 27 \\
Decline to respond - very low numbers & 24 & 22 \\
5 or more & 7 & 15 \\
Total responses & $\mathbf{1 3 5}$ & $\mathbf{1 3 6}$
\end{tabular}


Table 2: Number of staff aged 50 and above subject to formal performance processes, by role, responding institutions, 2013 and 2014

\begin{tabular}{lcc} 
& Academic & Support Staff \\
\hline No data held & 25 & 26 \\
0 & 52 & 46 \\
$0<\mathrm{n}<5$ & 26 & 27 \\
Decline to respond - very low numbers & 23 & 22 \\
5 or more & 8 & 16 \\
Total responses & $\mathbf{1 3 4}$ & $\mathbf{1 3 7}$
\end{tabular}


Table 3: Staff subject to performance processes, by role and age, 2013 and 2014

\begin{tabular}{lrrrr} 
& Academic & Academic & Support & Support \\
& $\mathbf{5 0}+$ & All ages & $\mathbf{5 0 +}$ & All ages \\
\hline No data held & 25 & 21 & 26 & 22 \\
0 & 52 & 40 & 46 & 28 \\
$0<\mathrm{n}<5$ & 26 & 33 & 27 & 30 \\
Decline to respond - very low numbers & 23 & 22 & 22 & 18 \\
5 or more & 8 & 14 & 16 & 35 \\
Total responses & 134 & 130 & 137 & 133
\end{tabular}


Table 4: Composition of UK higher education academic staff by age group and mode of employment, 2012-13 (Adapted from Higher Education Statistics Agency)

\begin{tabular}{llll} 
Age group & $\begin{array}{c}\text { Number of full } \\
\text { time academic staff }\end{array}$ & $\begin{array}{c}\text { Number of part } \\
\text { time academic staff }\end{array}$ & $\begin{array}{c}\text { Per cent of age } \\
\text { group working } \\
\text { part-time }\end{array}$ \\
\hline 30 and under & 15200 & 8925 & 36.99 \\
$31-40$ years & 37940 & 14590 & 27.77 \\
$41-50$ years & 35470 & 16090 & 31.21 \\
$51-60$ years & 27600 & 13540 & 32.91 \\
61 and over & 6290 & 9935 & 61.23 \\
Total & 122500 & 63090 & 33.99
\end{tabular}


Table 5: Full-time academic staff (excluding atypical) by age group and salary range 2015/16 (Source: Higher Education Statistics Agency, Table E)

\begin{tabular}{|c|c|c|c|c|c|c|c|}
\hline & & & $\begin{array}{r}\text { Contract } \\
\text { salary }\end{array}$ & & & & \\
\hline & $\begin{array}{r}\text { Contract } \\
\text { salary }\end{array}$ & $\begin{array}{r}\% \text { of staff } \\
\text { in age }\end{array}$ & $\begin{array}{r}\geq £ 43,758 \\
\text { and }\end{array}$ & $\begin{array}{c}\% \text { of staff } \\
\text { in age }\end{array}$ & $\begin{array}{r}\text { Contract } \\
\text { salary }\end{array}$ & $\begin{array}{r}\% \text { of staff } \\
\text { in age }\end{array}$ & \\
\hline & $<£ 43,758$ & bracket & $<£ 58,754$ & bracket & $\geq £ 58,754$ & bracket & Total \\
\hline \multicolumn{8}{|l|}{ Age group } \\
\hline 25 and under & 1965 & 99 & 15 & 1 & 0 & 0 & 1975 \\
\hline $26-30$ & 14910 & 96 & 490 & 3 & 85 & 1 & 15480 \\
\hline $31-35$ & 18380 & 78 & 4830 & 20 & 460 & 2 & 23670 \\
\hline $36-40$ & 9975 & 49 & 8765 & 43 & 1775 & 9 & 20510 \\
\hline $41-45$ & 5035 & 28 & 9325 & 51 & 3945 & 22 & 18300 \\
\hline $46-50$ & 3445 & 19 & 9265 & 50 & 5820 & 31 & 18530 \\
\hline $51-55$ & 2405 & 14 & 8300 & 48 & 6490 & 38 & 17195 \\
\hline $56-60$ & 1360 & 11 & 5585 & 46 & 5290 & 43 & 12235 \\
\hline $61-65$ & 535 & 9 & 2255 & 39 & 3000 & 52 & 5795 \\
\hline 66 and over & 120 & 9 & 420 & 32 & 785 & 59 & 1325 \\
\hline Total & 58120 & 43 & 49250 & 36 & 27650 & 20 & 135015 \\
\hline
\end{tabular}


Table 6: Academic staff by contract level, age and sex 2013/14 (Source: Higher Education Statistics Agency)

\begin{tabular}{lcccccccccc} 
& \multicolumn{3}{c}{ Professor } & \multicolumn{3}{c}{ Other senior academic } & \multicolumn{2}{c}{ Other academic } & Total \\
Age group & F & M & F \% & F & M & F \% & F & M & F \% \\
\hline $56-60$ & 920 & 2780 & 24.9 & 435 & 890 & 32.8 & 6575 & 7290 & 47.4 & 18890 \\
$61-65$ & 580 & 2495 & 18.9 & 170 & 550 & 23.6 & 3205 & 4930 & 39.4 & 11930 \\
$66+$ & 240 & 1485 & 13.9 & 35 & 130 & 21.2 & 1160 & 2590 & 30.9 & 5645
\end{tabular}




\section{University Library}

\section{- M M N E R VA A gateway to Melbourne's research publications}

Minerva Access is the Institutional Repository of The University of Melbourne

Author/s:

Blackham, A

Title:

Does removing default retirement ages benefit individuals? A comparative empirical case study of the university sector

Date:

2021

Citation:

Blackham, A. (2021). Does removing default retirement ages benefit individuals? A comparative empirical case study of the university sector. International Journal of Discrimination and the Law, 21 (2), pp.77-93. https://doi.org/10.1177/13582291211010418.

Persistent Link:

http://hdl.handle.net/11343/265935 